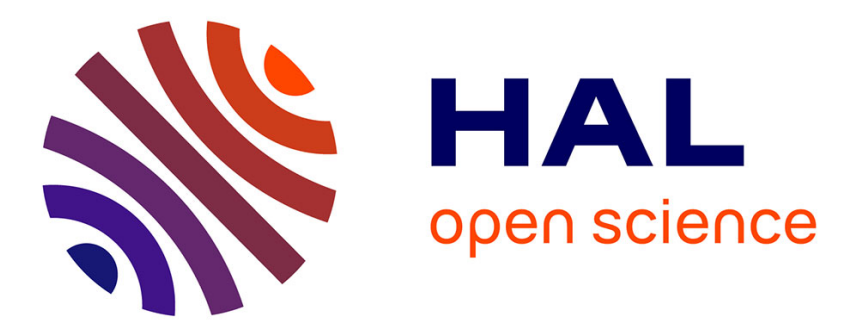

\title{
New procedure for extraction of algal lipids from wet biomass: A green clean and scalable process.
}

\author{
Celine Dejoye Tanzi, Maryline Abert, Farid Chemat
}

\section{To cite this version:}

Celine Dejoye Tanzi, Maryline Abert, Farid Chemat. New procedure for extraction of algal lipids from wet biomass: A green clean and scalable process.. Bioresource Technology, 2013, 134, pp.271275. 10.1016/j.biortech.2013.01.168 . hal-01328660

\section{HAL Id: hal-01328660 https://hal.science/hal-01328660}

Submitted on 29 May 2020

HAL is a multi-disciplinary open access archive for the deposit and dissemination of scientific research documents, whether they are published or not. The documents may come from teaching and research institutions in France or abroad, or from public or private research centers.
L'archive ouverte pluridisciplinaire HAL, est destinée au dépôt et à la diffusion de documents scientifiques de niveau recherche, publiés ou non, émanant des établissements d'enseignement et de recherche français ou étrangers, des laboratoires publics ou privés. 


\section{Accepted Manuscript}

New procedure for extraction of algal lipids from wet biomass: A green clean and scalable process

Celine Dejoye Tanzi, Maryline Abert Vian, Farid Chemat

PII: S0960-8524(13)00200-9

DOI: http://dx.doi.org/10.1016/j.biortech.2013.01.168

Reference: BITE 11332

To appear in:

\section{Bioresource Technology}

Received Date: $\quad 13$ December 2012

Revised Date: $\quad 25$ January 2013

Accepted Date: $\quad 30$ January 2013

Please cite this article as: Tanzi, C.D., Vian, M.A., Chemat, F., New procedure for extraction of algal lipids from wet biomass: A green clean and scalable process, Bioresource Technology (2013), doi: http://dx.doi.org/10.1016/ j.biortech.2013.01.168

This is a PDF file of an unedited manuscript that has been accepted for publication. As a service to our customers we are providing this early version of the manuscript. The manuscript will undergo copyediting, typesetting, and review of the resulting proof before it is published in its final form. Please note that during the production process errors may be discovered which could affect the content, and all legal disclaimers that apply to the journal pertain. 


\title{
clean and scalable process
}

\author{
Celine Dejoye Tanzi, Maryline Abert Vian*, Farid Chemat \\ University of Avignon, INRA, UMR408, 84000 Avignon, France \\ Corresponding author: \\ maryline.vian@univ-avignon.fr
}

\begin{abstract}
A new procedure, called Simultaneous Extraction and Distillation Process (SDEP), for lipid extraction from wet microalgae (Nannochloropsis oculata and Dunaliella salina) was reported.This method does not require a pre-drying of the biomass and employs alternative solvents such as d-limonene, $\alpha$-pinene and p-cymene. This procedure has been compared with Soxhlet extraction (Sox) and Bligh \& Dyer method (B\&D). For $N$. oculata, results showed that SDEP-cymene provided similar lipid yields to B\&D (21.45\% and 23.78\%), while SDEP-limonene and pinene provided lower yields (18.73\% and $18.75 \%$ respectively). For D. salina, SDEP-Pinene provided the maximum lipid yield (3.29\%) compared to the other solvents, which is quite close to B\&D result $(4.03 \%)$. No significant differences in terms of distribution of lipid classes and fatty acid composition have been obtained for different techniques. Evaluation of energy consumption indicates a substantial saving in the extraction cost by SDEP compared to the conventional extraction technique, Soxhlet.
\end{abstract}

Keywords: Wet lipid Extraction, Microalgae, Nannochloropsis oculata, Dunaliella salina, Terpenes

\section{Introduction}

Petroleum reserves depletion and global climate change have strongly encouraged the development of fuel production from various feedstocks such as 
vegetable oils, waste cooking oils, animal fat and microalgae. Among these options, microalgae have been recognized as potential good sources for biofuel production because they synthesize and accumulate large quantities of neutral lipids (20-50\% dry weight of biomass) and grow at high rates (Demirbas, 2008). In addition, microalgae can grow on non-arable, nutrient-poor land that cannot support conventional agriculture (Singh and Gu, 2010). A recent life-cycle assessment (LCA) of biofuel production from microalgae feedstocks mentioned that drying and n-hexane extraction accounted for up to $90 \%$ of the total process energy (Lardon et al., 2009). The extraction of crude oil is usually performed with petroleum solvents such as conventional n-hexane, chloroform and methanol, with techniques are highly energy-consumption and environmentally damaging (Halim et al., n.d.). Other extraction processes such as supercritical $\mathrm{CO}_{2}$, expelling, microwave-ultrasonic assisted extraction have also been reported (Cheng et al., 2011). Many processes have been investigated and reported for converting directly wet algae to crude biodiesel or biocrude (Anastasakis and Ross, 2011; Biller and Ross, 2011; Biller et al., 2011;Patil et al., 2011). But this biocrude differs from biodiesel that we want to extract as it is composed primarily of hydrocarbons in contrast to biodiesel which is composed of lipids in particular FAME after transesterification.

However, various conventional methods are available for oil extraction, but they generally require long extraction times, petroleum-based solvents, dried biomass with water content no more than $10 \%$ and high energy inputs. Upon harvesting, typical microalgal concentrations in cultures range from about $0.1-1.0 \%(w / v)$ (Cooney et al., 2009). This means that as much as 1000 times the amount of water per unit weight of microalgae must be removed before attempting oil extraction. The microalgae paste obtained from centrifugation (dewatering step) contains as much as $c a .80 \%$ water 
content. Therefore energy consumption for drying microalgae is dramatically high. A lipid extraction step that eliminates biomass drying and petroleum solvent use could lead to significant energy and cost savings.

Here we propose a new procedure of lipid extraction from microalgae, such as Nannochloropsis oculata (N. oculata) and Dunaliella salina (D. salina), that does not require drying of the harvested microalgal biomass and employs bio-solvents recognized as environmentally safer (Virot et al., 2008). Terpenes are natural solvents existing both in the citrus fruits and in many other plants, with extraordinary technical and chemical properties. Mamidipally and Liu recently demonstrated that the industrial extraction of oil from rice bran was possible by using terpene such as d-limonene instead of the regular $n$-hexane (Mamidipally and Liu, 2004; Liu and Mamidipally, 2005).

Extracted lipids obtained using this new procedure, conventional Soxhlet with $n$ hexane and Bligh \& Dyer method have been compared in term of total lipid content, lipid classes distribution and fatty acid composition.

\section{Materials and methods}

2.1. Strain, culture and harvesting conditions

N. oculata and D. salina were obtained by Greensea Company (Meze, France). N. oculata was incubated in tubular reactor at ambient temperature under deficiency conditions to obtain a high rate of lipids in the biomass. $D$. salina was grown in photobioreactor at ambient temperature with good sunniness under favourable conditions. For both, harvesting is being performed by centrifugation, resulting in a $20 \%$ dry weight paste that is directly frozen $\left(-25^{\circ} \mathrm{C}\right)$.

2.2. Extraction methods for total lipids 
2.2.1 Bligh and Dyer method (B\&D)

Total lipids content of both microalgae was determined using a modified B\&D method (Bligh and Dyer, 1959) which is already described in Adam et al., 2012.

\subsubsection{Soxhlet method (Sox)}

Lipids were isolated from microalgae by means of Soxhlet extraction (F. Soxhlet, 1879). Lipids were extracted from 10 grams of dry microalgae for $8 \mathrm{~h}$ using $300 \mathrm{~mL}$ of n-hexane. After the extraction, solvent was eliminated with a vacuum rotary evaporator. Extractions were performed in triplicate and the mean values were reported. Lipid extracts were dried under a stream of $\mathrm{N}_{2}$ and re-suspended in solvent for HP-TLC or GC-FID analysis.

\subsubsection{SDEP method}

For SDEP extraction, $12 \mathrm{~g} \pm 0.5 \mathrm{~g}$ of $20 \%$ dry weight microalgae paste were placed in in a $500 \mathrm{~mL}$ round-bottomed flask. $100 \mathrm{~mL}$ of terpene solvent (p-cymene, d-limonene or $\alpha$-pinene) was added in order to immerse the wet microalgae sample. The roundbottomed flask was surmounted by a modified Dean stark receiver with a 3-way valve and fitted with a condenser (Fig. 1). At the beginning of the experiment (step 1), the electrical heating was maximized until collection of the first droplets of microalgae water in the modified Dean stark receiver with a 3-way valve. Then the heating was adapted until most of the water had been distilled and it was continued to allow lipid extraction step (step 2) with terpene solvent. The extraction was performed for $30 \mathrm{~min}$. Then, the terpene elimination took place (step 3 and 4) and for that water was reintroduced by adjusting the 3-way valve to form a binary water-terpene mixture. To eliminate d-limonene from the distillation flask, we used the property that terpenes are traditionally extracted from their matrix by using a technique called hydrodistillation 
thus inducing the use of an azeotropic distillation to below the boiling point of terpene under the boiling point of the water (boiling point of the azeotrope : $97.4{ }^{\circ} \mathrm{C}$ ). Terpene solvent was recovered from the water layer by phase separation in the modified Dean stark receiver and the extracted lipids were recovered from the water layer by phase separation in the distillation round-bottomed flask. Thus, the SDEP procedure was allowed elimination of microalgae water, extraction of lipids and elimination of terpene solvent in a single "in situ" step. Terpene solvent was recuperated at $100 \%$ and purity levels show that it can be recycled for other uses, including other SDEP processes. Lipid extracts were analysed by GC-FID (against an external calibration with the pure solvent) and did not contain contamination by solvent (less than $0.01 \%$ of solvent in lipid extract). Extractions were performed in triplicate and the mean values were reported. Lipid extracts were dried under a stream of nitrogen and re-suspended in solvent without purification for HP-TLC or GC-FID analysis.

\subsection{Analysis of total lipids}

\subsubsection{Gravimetry}

Total lipid content was quantified by weight after total drying.

2.3.2. High Performance Thin-Layer Chromatography (HP-TLC)

Lipids were detected by charring and quantified using a CAMAG 3 TLC scanning densitometer (CAMAG, Muttenz, Switzerland) with identification of the classes against known polar and neutral lipid standards. Typically, Lipid extract was loaded as a spot onto $20 \times 10 \mathrm{~cm}$ silica gel 60 F254 HPTLC plates (Merck KGaA, Germany) using an ATS 5 automatic TLC sampler (Camag, Switzerland). Plates were then developed in an ADC2 automatic developing chamber (CAMAG, Switerland) using first a methyl acetate/isopropanol/chloroform/methanol/KCl (0.25\% solution) (25:25:25:10:9) mixture 
running to a height of $5.5 \mathrm{~cm}$ from the origin and then a n-hexane/diethyl ether/glacial acetic acid mixture (80:20:2) to a height of $8.5 \mathrm{~cm}$ from the origin. After dried, the plate was dipped for 6s in a modified $\mathrm{CuSO}_{4}$ reagent $\left(20 \mathrm{~g} \mathrm{CuSO}_{4}, 200 \mathrm{ml}\right.$ methanol, $8 \mathrm{ml}$ $\mathrm{H}_{2} \mathrm{SO}_{4}$, and $8 \mathrm{ml} \mathrm{H}_{3} \mathrm{PO}_{4}$ ) then heated at $141^{\circ} \mathrm{C}$ for $30 \mathrm{~min}$ on a TLC plate heater and finally scanned using a TLC Scanner 3 with WinCATs software (CAMAG). The densitometry data are reported as values which are expressed as percent of lipid class in total microalgae lipids.

\subsubsection{GC Analysis}

Fatty acids methyl esters (FAMEs) were separated, identified and quantified by gas chromatography coupled with flame ionization detector (GC-FID)using the method already described by Adam et al., 2012.

\section{Results and discussion}

\subsection{Recovery of Crude lipids}

The measurement of lipids recovery was based on the total amount of FAMEs in each sample. So it is a real yield in total fatty acids, and it is certainly a much more accurate value than a yield obtained by gravimetric method. Table 1 shows the results of both microalgae for each extraction method. Three extraction methods, B\&D, SDEP and Sox were tested with different solvents. Use of B\&D extraction is the commonly accepted method for lipid extraction from biological tissues due to its high lipid yields (Certik et al., n.d.). Therefore, the B\&D method was selected as standard to compare other extraction technique. As mentioned in Table 1, B\&D method yielded 23.78\% and 4.03\% lipids content for $N$. oculata and D. salina respectively. Crude lipids of $N$. oculata and D. salina obtained by SDEP procedure with three terpenes were higher than Sox and slightly lower than B\&D reference method. First, these results can be explained 
by the difference of polarity between solvents; Liu and Mamidipally (Mamidipally and Liu, 2004; Liu and Mamidipally, 2005) have already noted this effect that might be due to the slightly more polar nature of terpenes and much more polar nature of methanol/chloroforme mixture compared with $n$-hexane. In addition, in SDEP procedure the matrix is in direct contact with the boiling solvent which is not the case with the conventional Soxhlet. A higher dissolving ability of terpenes for lipids might also be pointed out by the higher temperature used to boil this solvent which could produce a lower viscosity of the analytes in the matrix and, accordingly, a better diffusion rate of the solute from the solid phase to the solvent.

\subsection{Lipids class composition}

Similar to higher plants, microalgal lipids are composed of neutral lipids and polar lipids. Under nutrient stress conditions, many microalgae tend to accumulate neutral lipids (consist of triacylglycerols (TAG), diacylglycerols (DAG), monoacylglycerols (MAG) and free fatty acids (FFA)) and form lipid droplet localized in the cytoplasm as a storage form of carbon and energy. Neutral lipids of the extracts were separated using high-performance thin-layer chromatography (HP-TLC), quantified with densitometry and presented as \% of lipid class in total lipids extracted with B\&D, SDEP and Sox for both microalgae. Four standards in a mixture of monoacylglycerol (MAG), diacylglycerol (DAG), triacylglycerol (TAG) and free fatty acids (C18) were deposited on the plate. For N. oculata, HP-TLC results confirm that TAG, DAG and FFA were the main components of the extracted lipids, but they contributed to the total lipid content in different amounts. As shown in Fig. 2, TAG made up an important percentage of total lipids (between 57 and 69\% according to extraction method). Regarding D.salina, the amount of TAG for B\&D method is about $60 \%, 54 \%$ for Sox and ranging from 50 to 
$57 \%$ for SDEP procedures. The SDEP procedure with p-cymene solvent gives a higher quantity of TAG than d-limonene and $\alpha$-pinene. Results obtained with the SDEP method including different terpene were almost similar with those obtained by both conventional Sox and B\&D method.

\subsection{Fatty acid compositions}

Table 1 shows the classes' variability of FAMEs in connection with the extraction method used. The nature of FAMEs composition in $N$. oculata and D. salina was determined by GC analysis. According to Table 1, the main fatty acids for N. oculata were palmitic (C16:0), oleic (C18:1), linoleic (C18:2) and linolenic (C18:3) acids. These four fatty acids represent more than $80 \%$ of the total fatty acid composition of the extracted oil. Other fatty acids such as myristic (C14:0), palmitoleic (C16:1), palmitolenic $(\mathrm{C} 16: 2)$, hirigonic $(\mathrm{C} 16: 3)$ or stearic $(\mathrm{C} 18: 0)$ acids were also noted with a less predominant peak area. Arachidic (C20:0) and behenic (C22:0) acids were found in trace levels. No significant differences were detected according different extraction methods and solvents. The fatty acid composition of $N$. oculata sp. displayed in Table 1 is different to the profile presented by Adam et al. (Adam et al., 2012). Despite similar results regarding the respective proportions of $\mathrm{C} 16: 0$ and $\mathrm{C} 14: 0$, the authors report $N$. oculata to contain particularly high levels of C16:1 and C25:3, with corresponding reduction in C18:1, C18:2 and C18:3. Fatty acid profile of microalgal species is known to be function of its culturing conditions and environmental conditions (Olofsson et al., 2012). For D.salina sp., palmitic (C16:0), oleic (C18:1n9), hexadecatetraenoic (C16:4), linoleic (C18:2) and linolenic (C18:3) acids were identified as the principal fatty acids in $D$. salina extracted lipids. The data in table reveals that total unsaturated fatty acids were about $45-60 \%$, while saturated fatty acids were about $40-50 \%$. Results obtained 
with SDEP method were almost similar with those obtained by both conventional Sox extraction and B\&D method. The sum percentages of saturated, mono- and polyunsaturated fatty acids were in line with those of several tables dealing with the fatty acid composition of N. oculata and D. salina oil found in literature. As a conclusion, it can be said that the proportion of the different fatty acids as well as the proportion of SFAs, PUFAs, or MUFAs has not been affected by the unusual conditions used in our experiment, in other words, the use of terpenes as solvent do not involve extraneous effects and/or artefacts on the composition of the lipids extracted.

\subsection{Energy consumption}

We conducted a comparison on energy consumption of SDEP process and the current method to extract lipids, Soxhlet. Alternatively, the input power consumption was monitored using a separate Wattmeter at the entrance of electrical heater power supply (i.e. at the entrance of electrical heater, rotary evaporator and cooler power supply). For Soxhlet extraction, drying biomass is required. So, in our calculation we have taken into account the freeze-drying of microalgae for $48 \mathrm{~h}$. We have added the energy consumption of all apparatus involved in each extraction technique. The energy requirement to perform the extraction, based on the power consumptions for $1 \mathrm{~g}$ of extracted lipids, was $8.84 \mathrm{kWh}$ for Soxhlet while this value was $2.15 \mathrm{kWh}$ for SDEP. This indicates a substantial saving in the extraction cost by SDEP compared to the conventional extraction technique, Soxhlet.

\section{Conclusion}

The new procedure has undergone reproducible results in a substantially shorter time. The efficiency of SDEP is considerably higher than the conventional procedure in terms of lipid yield and if we take into account short distillation and extraction times 
required, cost and energy used of the process. This study has clearly demonstrated that this procedure can be used to extract lipid directly from wet microalgae with an extraction yield similar to that of the B\&D method, with only minor variation in the fatty acids distribution.

\section{Acknowledgements}

The authors are grateful for the financial support of the Salinalgue program (FUIFrance) coordinated by La Compagnie du Vent (Montpellier, France).

\section{References}

1. Adam, F., Abert-Vian, M., Peltier, G., Chemat, F., 2012. "Solvent-free" ultrasound-assisted extraction of lipids from fresh microalgae cells: A green, clean and scalable process. Bioresource Technology 114, 457-465.

2. Anastasakis, K., Ross, A.B., 2011. Hydrothermal liquefaction of the brown macro-alga Laminaria Saccharina: Effect of reaction conditions on product distribution and composition. Bioresource Technology 102, 4876-4883.

3. Biller, P., Riley, R., Ross, A.B., 2011. Catalytic hydrothermal processing of microalgae: Decomposition and upgrading of lipids. Bioresource Technology $102,4841-4848$.

4. Biller, P., Ross, A.B., 2011. Potential yields and properties of oil from the hydrothermal liquefaction of microalgae with different biochemical content. Bioresource Technology 102, 215-225.

5. Bligh, E.G., Dyer, W.J., 1959. A rapid method of total lipid extraction and purification. Biochemistry and Cell Biology 37, 911-917. 
6. Certik, M., Andrasi, P., Sajbidor, J., n.d. Effect of extraction methods on lipid yield and fatty acid composition of lipid classes containing $\gamma$-linolenic acid extracted from fungi. Journal of the American Oil Chemists' Society 73, 357365.

7. Cheng, C.-H., Du, T.-B., Pi, H.-C., Jang, S.-M., Lin, Y.-H., Lee, H.-T., 2011. Comparative study of lipid extraction from microalgae by organic solvent and supercritical CO2. Bioresource Technology 102, 10151-10153.

8. Cooney, M., Young, G., Nagle, N., 2009. Extraction of Bio-oils from Microalgae. Separation \& Purification Revs. 38, 291-325.

9. Demirbas, A., 2008. Comparison of transesterification methods for production of biodiesel from vegetable oils and fats. Energy Conversion and Management 49, $125-130$.

10. F. Soxhlet, 1879. . Dinglers' Polyt. J. 232, 461.

11. Halim, R., Danquah, M.K., Webley, P.A., n.d. Extraction of Oil from Microalgae for Biodiesel Production: A Review. Biotechnology Advances.

12. , A., Sialve, B., Steyer, J.-P., Bernard, O., 2009. Life-Cycle Assessment of Biodiesel Production from Microalgae. Environ. Sci. Technol. $43,6475-6481$.

13. Liu, S.X., Mamidipally, P.K., 2005. Quality Comparison of Rice Bran Oil Extracted with d-Limonene and Hexane. Cereal Chemistry 82, 209-215.

14. Mamidipally, P.K., Liu, S.X., 2004. First approach on rice bran oil extraction using limonene. European Journal of Lipid Science and Technology 106, 122125. 
15. Olofsson, M., Lamela, T., Nilsson, E., Bergé, J.P., Del Pino, V., Uronen, P., Legrand, C., 2012. Seasonal Variation of Lipids and Fatty Acids of the Microalgae Nannochloropsis oculata Grown in Outdoor Large-Scale Photobioreactors. Energies 5, 1577-1592.

16. Patil, P.D., Gude, V.G., Mannarswamy, A., Deng, S., Cooke, P., MunsonMcGee, S., Rhodes, I., Lammers, P., Nirmalakhandan, N., 2011. Optimization of direct conversion of wet algae to biodiesel under supercritical methanol conditions. Bioresource Technology 102, 118-122.

17. Singh, J., Gu, S., 2010. Commercialization potential of microalgae for biofuels production. Renewable and Sustainable Energy Reviews 14, 2596-2610.

18. Virot, M., Tomao, V., Ginies, C., Visinoni, F., Chemat, F., 2008. Green procedure with a green solvent for fats and oils' determination: Microwaveintegrated Soxhlet using limonene followed by microwave Clevenger distillation. Journal of Chromatography A 1196-1197, 147-152. 
2
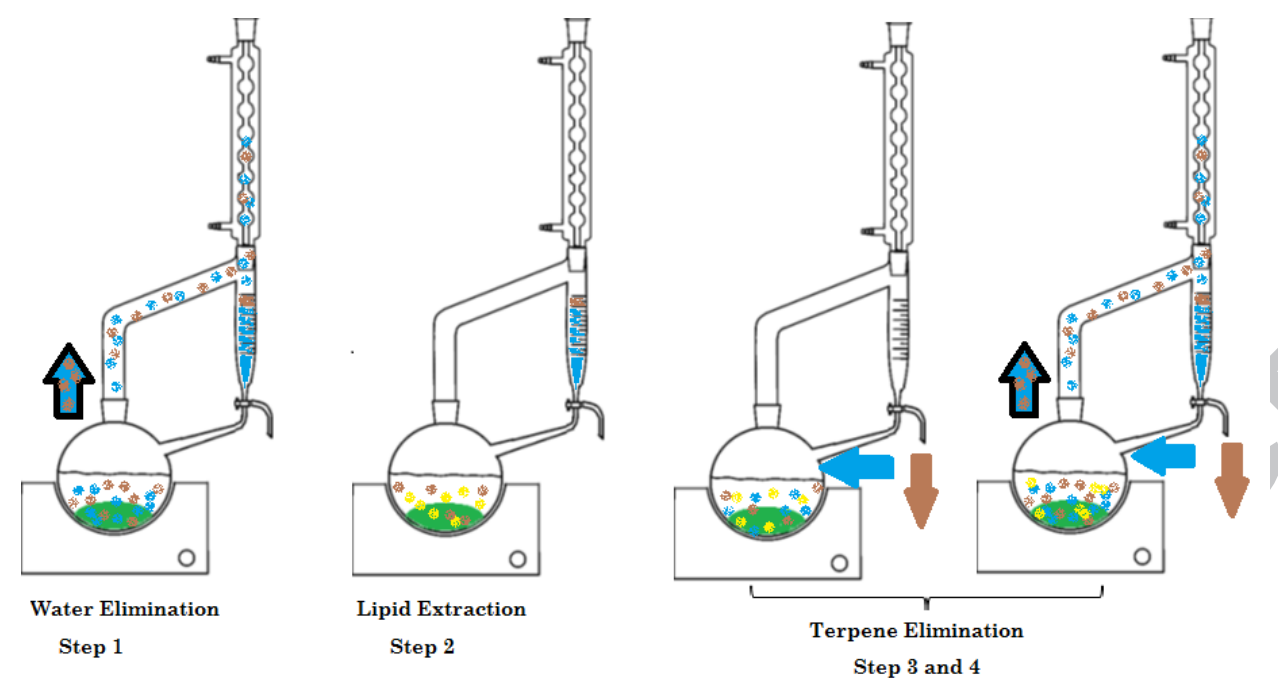

Fig. 1. Simultaneous Distillation Extraction Process (SDEP) (blue: water biomass, brown: terpene solvent, yellow: lipids, green: microalgae) 
1

2

3

4

5

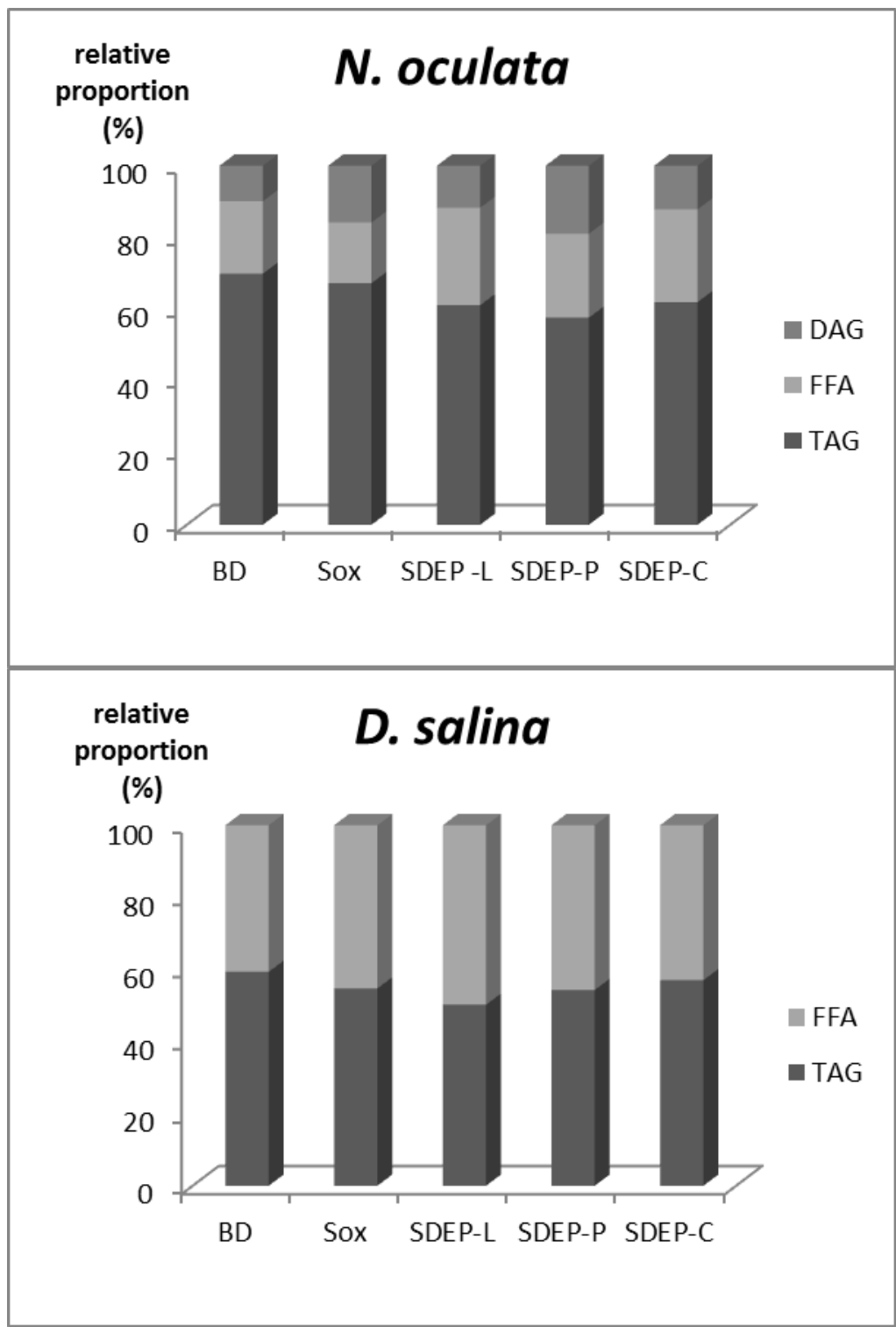

Fig. 2. Distribution of lipid classes by HP-TLC 
Table 1: Crude lipids, distribution of lipid class and fatty acid composition of extracts obtained by different extraction methods. (PUFAs polyunsaturated fatty acids, MUFAs monounsaturated fatty acids, SFAs Saturated fatty acids)

\begin{tabular}{|c|c|c|c|c|c|c|c|c|c|c|c|c|c|c|c|c|c|c|c|c|}
\hline \multirow[b]{4}{*}{ Lipids Yield (\%) } & \multicolumn{10}{|c|}{ N. oculata } & \multicolumn{10}{|c|}{ D. salina } \\
\hline & \multirow{2}{*}{\multicolumn{2}{|c|}{$\mathrm{B} \& \mathrm{D}$}} & \multicolumn{6}{|l|}{ SDEP } & \multirow{2}{*}{\multicolumn{2}{|c|}{ Sox }} & \multirow{2}{*}{\multicolumn{2}{|c|}{$\mathrm{B} \& \mathrm{D}$}} & \multicolumn{6}{|l|}{ SDEP } & \multirow{2}{*}{\multicolumn{2}{|c|}{ Sox }} \\
\hline & & & \multicolumn{2}{|c|}{ d-limonene } & \multicolumn{2}{|c|}{$\alpha$-pinene } & \multicolumn{2}{|c|}{ p-cymene } & & & & & d-limo & & $\alpha$-pine & & p-cyme & & & \\
\hline & 23.78 & \pm 2.13 & 18.73 & \pm 6.58 & 18.75 & \pm 3.01 & 21.45 & \pm 2.64 & 8.31 & \pm 1.05 & 4.03 & \pm 0.01 & 2.94 & \pm 0.02 & 3.29 & \pm 0.05 & 2.99 & \pm 0.01 & 1.90 & \pm 0.03 \\
\hline $\begin{array}{ll}\text { Lipid } & \text { class } \\
\text { composition } & \end{array}$ & & & & & & & & & & & & & & & & & & & & \\
\hline FFA : Free fatty acid & 20.21 & \pm 0.03 & 27.12 & \pm 0.12 & 23.42 & \pm 0.27 & 25.84 & \pm 0.32 & 16.92 & \pm 0.13 & 40.64 & \pm 0.36 & 49.77 & \pm 0.08 & 47.55 & \pm 0.32 & 42.95 & \pm 0.01 & 45.25 & \pm 0.09 \\
\hline TAG : Triacylglycerol & 69.94 & \pm 0.16 & 61.18 & \pm 0.05 & 57.67 & \pm 0.65 & 62.02 & \pm 0.82 & 67.30 & \pm 2.68 & 59.36 & \pm 0.02 & 50.23 & \pm 0.20 & 52.45 & \pm 0.05 & 57.05 & \pm 0.24 & 54.75 & \pm 0.04 \\
\hline DAG: Diacylglycerol & 9.85 & \pm 0.06 & 11.71 & \pm 0.06 & 18.91 & \pm 0.09 & 12.15 & \pm 0.15 & 15.78 & \pm 0.12 & - & & - & & - & & - & & - & \\
\hline $\begin{array}{ll}\text { Fatty } & \text { acids } \\
\text { composition } & \\
\text { Saturated } & \end{array}$ & & & & & & & & & & & & & & & & & & & & \\
\hline $\mathrm{C} 14: 0$ & 1.20 & \pm 0.02 & 1.52 & \pm 0.03 & 1.43 & \pm 0.01 & 0.72 & \pm 0.97 & 1.37 & \pm 0.10 & 3.37 & \pm 0.45 & 6.74 & \pm 0.17 & 3.69 & \pm 0.02 & 3.61 & \pm 0.01 & 1.01 & \pm 0.03 \\
\hline C16:0 & 20.65 & \pm 0.09 & 21.86 & \pm 0.41 & 21.90 & \pm 0.01 & 21.69 & \pm 0.03 & 21.55 & \pm 0.28 & 46.46 & \pm 0.31 & 34.84 & \pm 1.05 & 43.36 & \pm 0.15 & 42.66 & \pm 0.06 & 38.67 & \pm 1.65 \\
\hline $\begin{array}{l}\text { C18:0 } \\
\text { Mono-unsaturated }\end{array}$ & 1.62 & \pm 0.05 & 1.84 & \pm 0.11 & 1.75 & \pm 0.01 & 1.88 & \pm 0.09 & 1.72 & \pm 0.01 & 1.26 & \pm 0.04 & 3.13 & \pm 0.06 & 1.01 & \pm 0.03 & $\begin{array}{l}1.17 \\
\pm\end{array}$ & \pm 0.02 & 0.81 & \pm 0.07 \\
\hline C14:1 & - & & - & & - & & - & & & & 0.43 & \pm 0.01 & 2.02 & \pm 0.02 & 0.60 & \pm 0.01 & 0.48 & \pm 0.02 & 0.19 & \pm 0.02 \\
\hline C16:1(n-9) & 1.07 & \pm 0.01 & 1.25 & \pm 0.05 & 1.12 & \pm 0.01 & 1.10 & \pm 0.01 & 1.13 & \pm 0.02 & 0.69 & \pm 0.09 & 0.94 & \pm 0.09 & 0.91 & \pm 0.01 & 0.58 & \pm 0.01 & 1.52 & \pm 0.58 \\
\hline C16:1(n-7) & 2.76 & \pm 0.02 & 3.26 & \pm 0.01 & 3.11 & \pm 0.01 & 3.12 & \pm 0.05 & 2.83 & \pm 0.11 & 0.54 & \pm 0.01 & 1.88 & \pm 0.34 & 0.89 & \pm 0.01 & 0.52 & \pm 0.01 & 1.77 & \pm 0.24 \\
\hline C18:1(n-9) & 27.46 & \pm 0.04 & 26.03 & \pm 0.02 & 26.27 & \pm 0.11 & 26.62 & \pm 0.73 & 26.87 & \pm 0.36 & 6.50 & \pm 0.14 & 12.61 & \pm 0.19 & 7.55 & \pm 0.03 & 7.67 & \pm 0.01 & 6.80 & \pm 0.27 \\
\hline $\mathrm{C} 18: 1(\mathrm{n}-7)$ & 2.78 & \pm 0.02 & 2.59 & \pm 0.24 & 2.52 & \pm 0.11 & 2.45 & \pm 0.15 & 2.35 & \pm 0.04 & - & & - & & - & & - & & & \\
\hline Poly-unsaturated & & & & & & & & & & & & & & & & & & & & \\
\hline $\mathrm{C} 16: 2$ & 2.46 & \pm 0.01 & 2.73 & \pm 0.13 & 2.48 & \pm 0.01 & 2.46 & \pm 0.03 & 2.53 & \pm 0.03 & 0.08 & \pm 0.01 & 2.42 & \pm 0.08 & 1.04 & \pm 0.01 & 0.91 & \pm 0.01 & 0.82 & \pm 0.06 \\
\hline $\mathrm{C} 16: 3$ & 4.76 & \pm 0.03 & 4.84 & \pm 0.04 & 4.75 & \pm 0.03 & 4.74 & \pm 0.05 & 4.90 & \pm 0.07 & 1.18 & \pm 0.01 & 1.64 & \pm 0.06 & 0.37 & \pm 0.07 & 0.27 & \pm 0.01 & 0.91 & \pm 0.05 \\
\hline C16:4 & - & & - & & - & & - & & & & 9.22 & \pm 0.17 & 9.20 & \pm 0.03 & 9.16 & \pm 0.04 & 9.94 & \pm 0.01 & 8.37 & \pm 0.22 \\
\hline C18:2(n-6) & 14.70 & \pm 0.01 & 14.91 & \pm 0.09 & 15.08 & \pm 0.03 & 15.50 & \pm 0.64 & 15.14 & \pm 0.20 & 6.95 & \pm 0.09 & 7.89 & \pm 0.99 & 7.98 & \pm 0.15 & 7.65 & \pm 0.17 & 8.60 & \pm 0.50 \\
\hline C18:3(n-3) & 20.09 & \pm 0.07 & 19.18 & \pm 0.36 & 19.60 & \pm 0.01 & 19.73 & \pm 0.24 & 20.06 & \pm 0.32 & 20.32 & \pm 0.10 & 16.70 & \pm 0.10 & 23.44 & \pm 0.09 & 24.66 & \pm 0.05 & 30.54 & \pm 0.14 \\
\hline$\sum$ SFAs & 23.47 & & 25.22 & & 25.08 & & 24.28 & & 24.64 & & 51.09 & & 44.71 & & 48.06 & & 47.44 & & 40.49 & \\
\hline$\sum$ MUFAs & 34.07 & & 33.13 & & 33.01 & & 33.29 & & 33.18 & & 8.16 & & 17.44 & & 9.95 & & 9.25 & & 10.28 & \\
\hline$\sum$ PUFAs & 42.01 & & 41.66 & & 41.90 & & 42.43 & & 42.62 & & 37.75 & & 37.85 & & 41.99 & & 43.43 & & 49.24 & \\
\hline
\end{tabular}




\section{Highlights}

- A new extraction procedure of lipids from wet microalgae

- Nannochloropsis oculata and dunaliella salina were chosen as a microalgae

- Influence of operating parameters on the extraction yields will be studied

- Utilization of terpenes bio-solvents recognized as environmentally safer 